\title{
BBO CASE REPORT
}

\section{Angle Class I malocclusion and agenesis of lateral incisors*}

Fernanda Catharino Menezes Franco**

\begin{abstract}
Orthodontic planning for patients with agenesis of lateral incisors should include extremely relevant esthetic and functional considerations so that a satisfactory clinical result is achieved. Both space closure and space opening or maintenance have advantages and disadvantages that should be evaluated according to the patient's individual characteristics. Some of the important factors that affect planning are the skeletal pattern, the type of malocclusion and the color and shape of canines. This study reports on the treatment of a patient with Class I malocclusion and agenesis of lateral incisors, decreased overjet and overbite, and a tendency to open bite and crossbite. The clinical approach included palatal expansion followed by space closure using extraoral anchorage. This case was presented to the Committee of the Brazilian Board of Orthodontics and Facial Orthopedics (BBO) in the Free Case category as part of the requisites to obtain the $\mathrm{BBO}$ Diploma.
\end{abstract}

Keywords: Angle Class I. Tooth agenesis. Corrective orthodontics.

\section{INTRODUCTION}

A Caucasian girl aged 10 years and 4 months complained about her teeth esthetics because of the diastemas in the maxillary incisor region, according to herself and her parents. She reported good health except for occasional episodes of allergic rhinitis. The examination of family history showed cases of mandibular prognathism, and the family expressed their concern about the possible genetic transmission of this facial dysplasia.

How to cite this article: Franco FCM. Angle Class I malocclusion and agenesis of lateral incisors. Dental Press J Orthod. 2011 July-Aug;16(4):137-47.

\section{DIAGNOSIS}

Facial examination showed a mesocephalic pattern, no evident asymmetries, a straight profile, increased nasolabial angle and discrete upper lip retrusion. Analysis of the smile showed broad buccal corridors, a result of transverse deficiency in the maxilla, as well as a low smile line with reduced exposure of anterior teeth, a greatly relevant aspect in orthodontic treatment considering the patient's age. Intraoral examination showed low risk of caries and healthy periodontal tissues.

" The author report no commercial, proprietary, or financial interest in the products or companies described in this article.

* Case Report, category 5, approved by the Brazilian Board of Orthodontics and Dentofacial Orthopedics. (BBO).

** MSc in Orthodontics, Federal University of Rio de Janeiro, Rio de Janeiro, Brazil. Diplomate of the Brazilian Board of Orthodontics and Facial Orthopedics. Professor, School of Medicine and Public Health of Bahia, Salvador, Brazil. Professor, Graduate Program, Specialization Course of Orthodontics, Federal University of Bahia (UFBA), Salvador, Brazil. 
The patient presented Class I molar and canine occlusion, missing maxillary lateral incisors, reduced overbite and overjet, which indicated a tendency to open bite and crossbite in the anterior region. Additionally, the upper arch was triangular and atresic and there were spaces between the anterior teeth. The lower arch was also narrow and followed the shape of the upper arch, with marked lingual inclination and crowding in the anterior region (Figs 1 and 2).
The examination of periapical and panoramic radiographs confirmed agenesis of maxillary lateral incisors and showed that the roots of second molars were in an advanced stage of formation and that third molar germs were missing (Fig 3). Cephalometric analysis (Fig 4, Table 1) revealed a Class I $\left(\mathrm{ANB}=2^{\circ}\right)$ skeletal pattern, predominance of vertical growth $(\mathrm{SN}-\mathrm{GoGn}=$ $\left.40^{\circ}\right)$ and lingual inclination of mandibular incisors $\left(\mathrm{IMPA}=88^{\circ}\right)$.
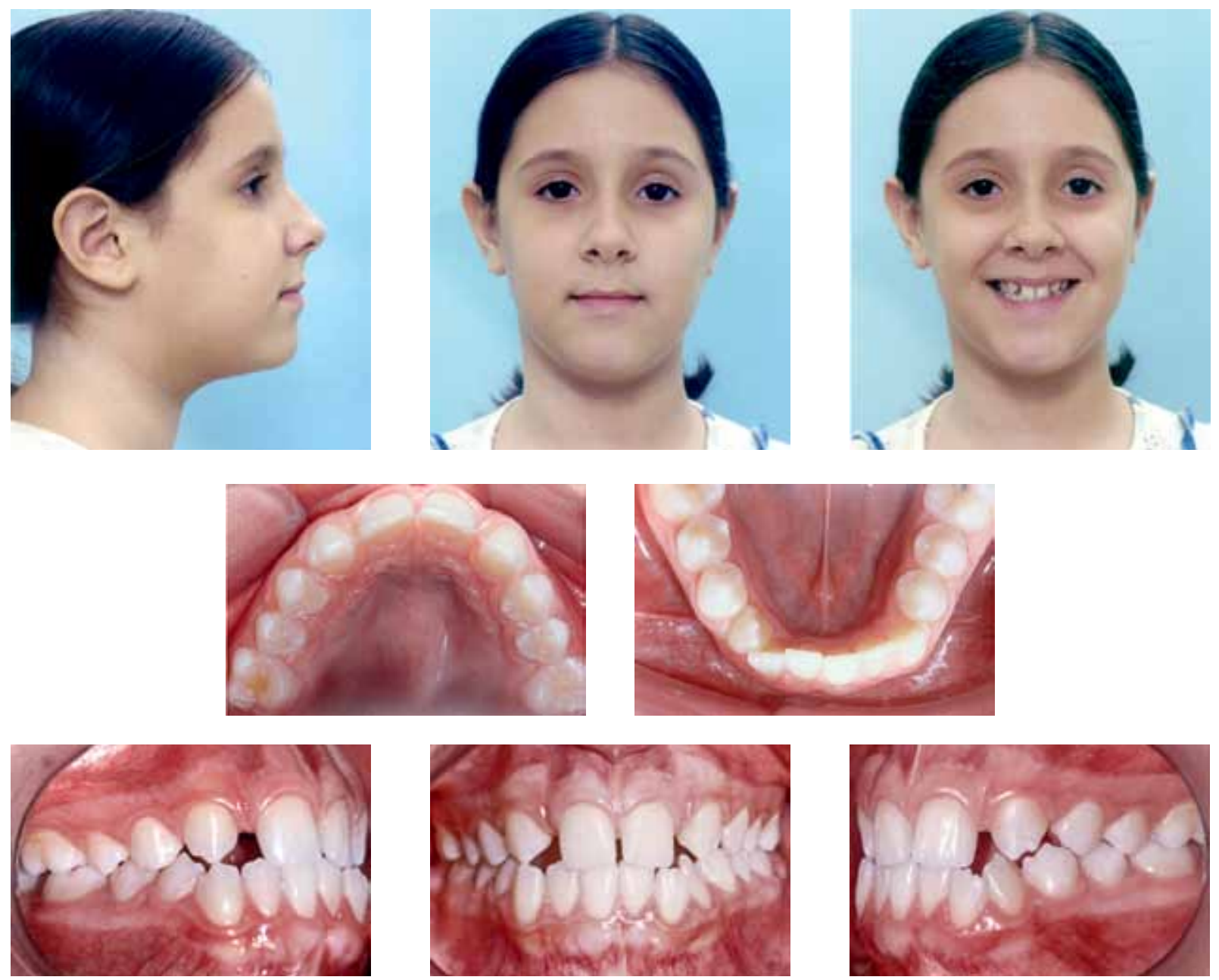

FIGURE 1 - Initial facial and intraoral photographs. 

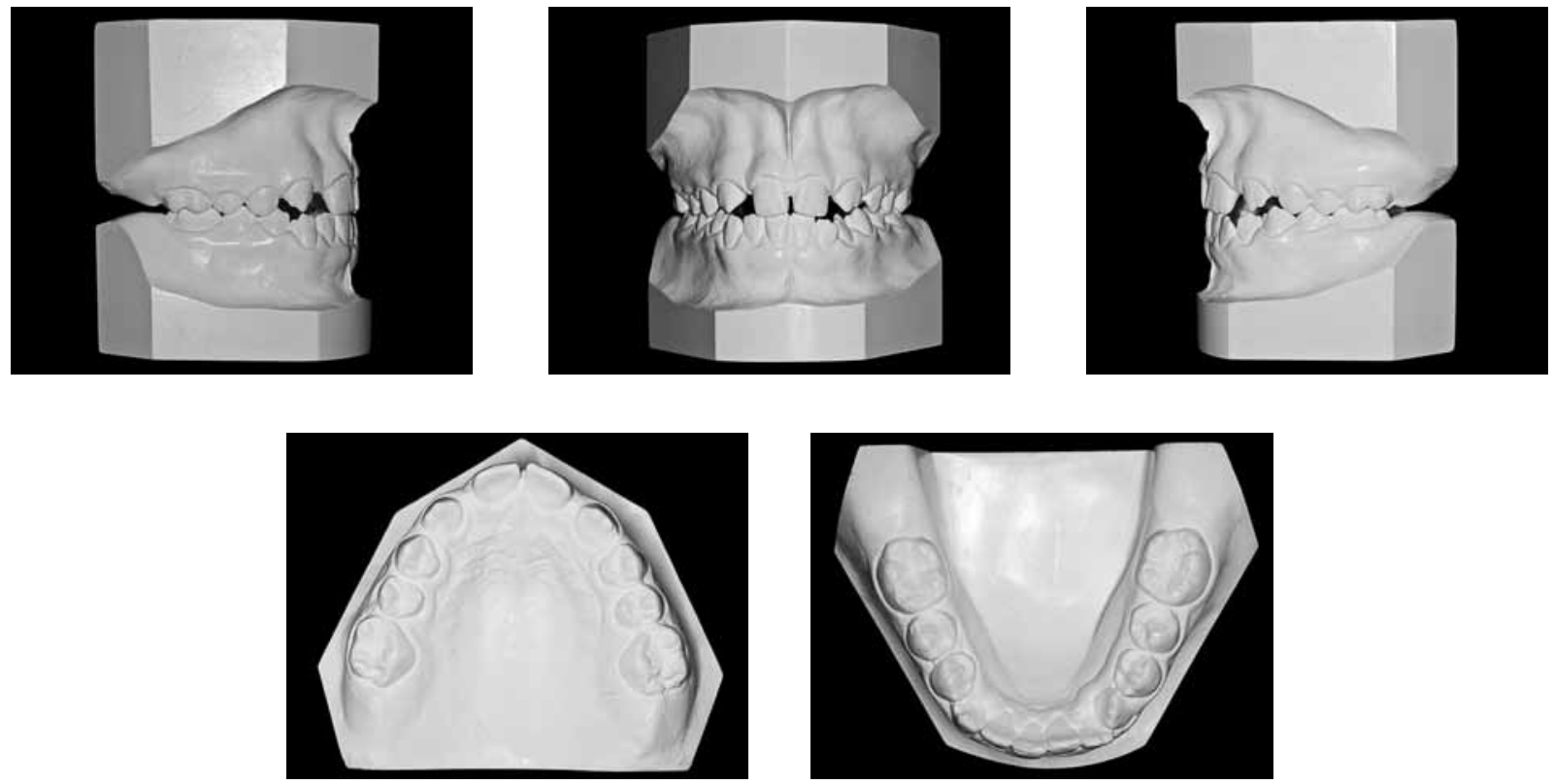

FIGURE 2 - Initial casts.
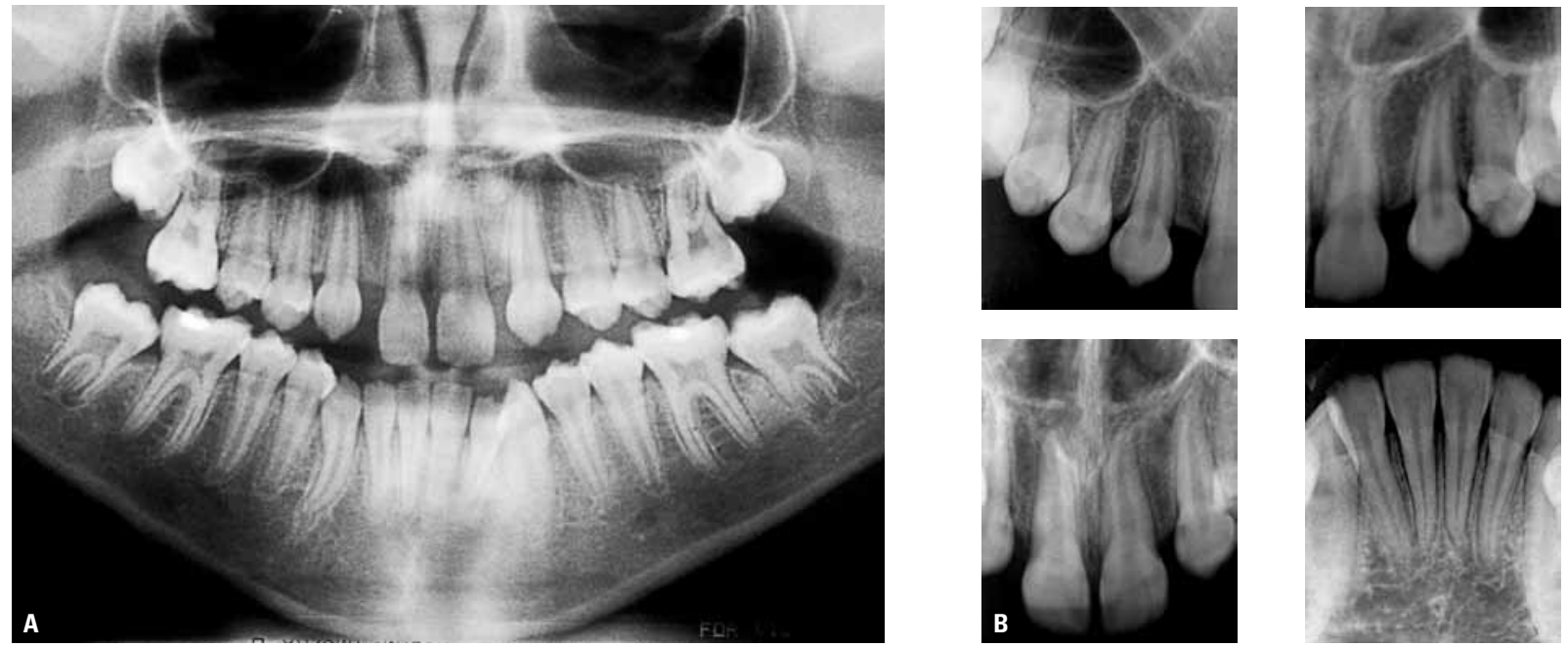

FIGURE 3 - Panoramic (A) and periapical (B) radiographs. 

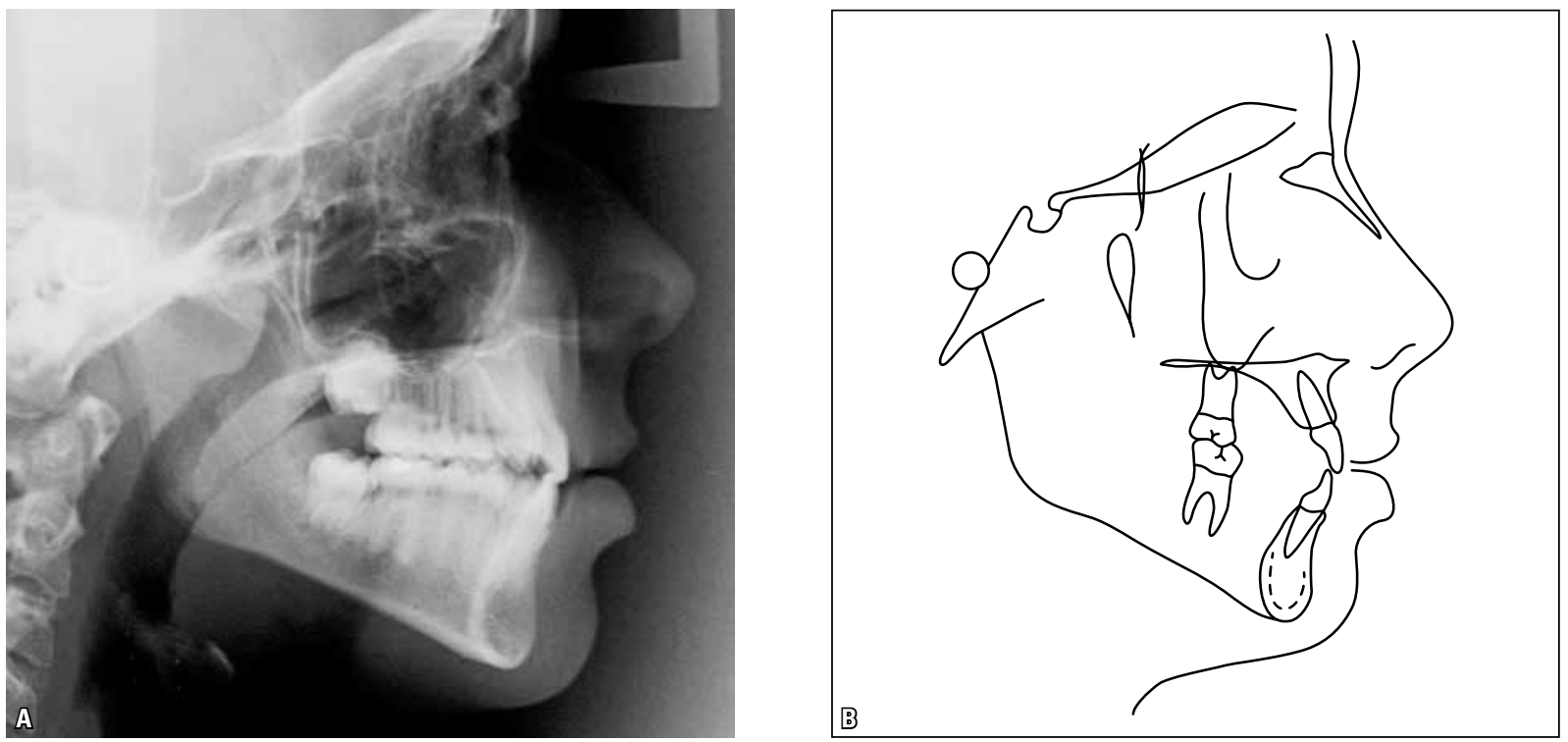

FIGURE 4 - Initial lateral cephalometric radiograph (A) and cephalometric tracing (B).

\section{TREATMENT OBJECTIVES}

Considering that the deficiency in the anterior region of the maxilla was one of the aspects that most affected the patient's smile esthetics, the main objective of the treatment was to improve arch shape. In addition to the esthetic benefits, palatal expansion would favor the axial adjustment of mandibular teeth and improve crowding in that region. We decided to close the spaces that corresponded to the missing maxillary lateral incisors by moving the canines and posterior teeth mesially. Another treatment objective was to restore the correct levels of overbite and overjet to achieve a better anterior positioning of the maxilla, control the tendency towards mandibular prognathism and, therefore, establish the harmony of facial and smile esthetics.

\section{TREATMENT PLAN}

A comprehensive treatment was planned and included fixed orthodontic apliances in the maxillary and mandibular arches after palatal expansion using a Hyrax expander associated with maxillary protraction using a facial mask. The purpose of the planned treatment was to increase the transverse dimension and to move the maxilla anteriorly to manage the tendency to crossbite and to define proper overjet.

First, the palatal appliance would be installed. On the second week of activation, the extraoral reverse traction (ERT) appliance would be placed. After expansion, during the six-month retention for the maxillary arch, the ERT would be kept in use, the fixed orthodontic appliance for the mandibular arch would be placed and mandibular alignment and leveling would begin. After the expander was removed, the maxillary fixed orthodontic appliance would be installed. To avoid the tendency towards anterior crossbite, space closure in the maxillary arch would use extraoral anchorage.

After space closure, occlusion would be improved using $0.019 \times 0.026$-in rectangular stainless steel archwires with individualized bends 
and torques according to esthetic and functional needs in cases of agenesis of lateral incisors. A removable wraparound retainer would by prescribed for the maxillary arch, and for the mandibular arch, a fixed retainer with a 0.028 -in stainless steel intercanine wire.

\section{TREATMENT PROGRESSION}

The Hyrax palatal expander was placed, and directions were given for two daily activations (1/4 of a turn of the screw every 12 hours) for three weeks. The patient experienced intense pain five days later, and instructions were given to reduce activations to once a day. The ERT appliance was placed on the second week; the initial force was $350 \mathrm{~g}$ on each side and progressively increased up to $500 \mathrm{~g}$, which was kept after expansion. Traction direction was adjusted according to the center of resistance of the maxillary bone to avoid unwanted maxillary rotations. Instructions were given to wear the ERT appliance for at least 14 hours per day. Because of the reduction in the number of activations, expansion lasted four weeks; significant opening of the interincisal diastema was achieved, and overjet increased $3 \mathrm{~mm}$.

After active expansion, a fixed orthodontic appliance with a $0.022 \times 0.028$-in slot was placed in the mandibular arch for its alignment and leveling. Palatal expansion allowed uprighting of the mandibular teeth, which had a lingual inclination in the beginning of the treatment. This movement promoted a gain in arch perimeter and resolved crowding in the anterior region.

The fixed orthodontic appliance was placed in the maxillary arch six months after retention and when radiographs confirmed suture ossification. After incisor alignment and leveling, the anterior spaces were closed as a result of the mesial movement of canines, which occupied the space corresponding to the missing lateral incisors. To avoid occlusal interferences, canines were reshaped, their torques were individualized, and their anatomic shape was that of the missing lateral incisors. The remaining spaces were closed by moving the posterior teeth mesially by using the ERT appliance as anchorage. This movement began with the first molar and followed, subsequently, up to the second molar. During finishing, the gingival margins of anterior teeth were adjusted to meet esthetic requirements in this area. The archwires for the final stage were made to have individualized torques for the canines in the sites of the missing teeth and for the premolars that replaced the canines. Posterior teeth were positioned to promote posterior guidance by mandibular excursion. Results were maintained by using an upper arch wraparound removable retainer and a fixed intercanine retainer for the lower arch.

\section{RESULTS}

The main objectives established in the beginning of the treatment were achieved, and esthetic and functional results were reasonably satisfactory. Palatal expansion resulted in a favorable increase in the transverse dimension of the maxilla, a more parabolic shape of the arches and proper buccal corridors, which contributed to satisfactory esthetic results (Fig 5). Palatal expansion also changed the shape of the mandibular arch. The shape coordination between arches allowed for uprighting the mandibular teeth that were lingually inclined at the beginning of the treatment and resulted in an increase in arch perimeter and resolution of crowding (Figs 5 and 6). Radiographs confirmed good parallel relationships between dental roots and a discrete apical rounding of maxillary incisors, compatible with orthodontic movement (Fig 7). An important radiographic finding in the final examination was internal root resorption at an initial stage in the maxillary right first molar. Referral to endodontic treatment in this phase ensured that the tooth was preserved. 

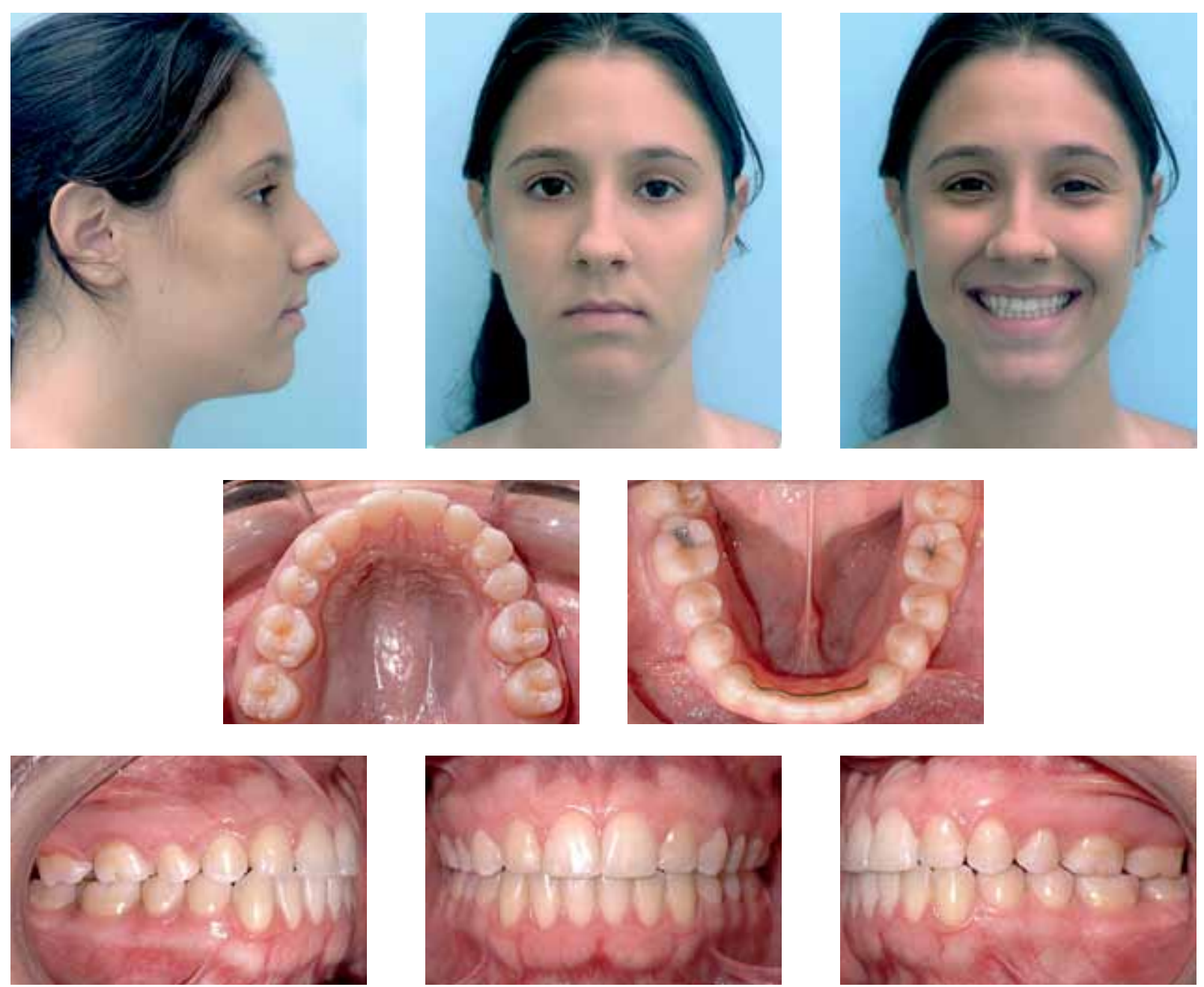

FIGURE 5 - Facial and intraoral final photographs.

The trend towards anterior crossbite was controlled by the action of the ERT appliance. Even during space closure by movement of the posterior teeth mesially, there was no direct application of force on the anterior teeth, which preserved their position and avoided unwanted effects on occlusion and profile. The effects of reverse traction mechanics were confirmed by cephalometry, which showed the maintenance of the maxillary position both in absolute values (initial and final
SNA equal to $76^{\circ}$ ) and in total superimposition (Figs 8 and 9).

Final occlusion had a good relationship between arches and a Class II molar relationship, and normal occlusion of mandibular canines and maxillary first premolars, as well as normal overbite and overjet. These results ensure functional balance and mandibular excursion without interferences, as well as healthy periodontal tissues. 

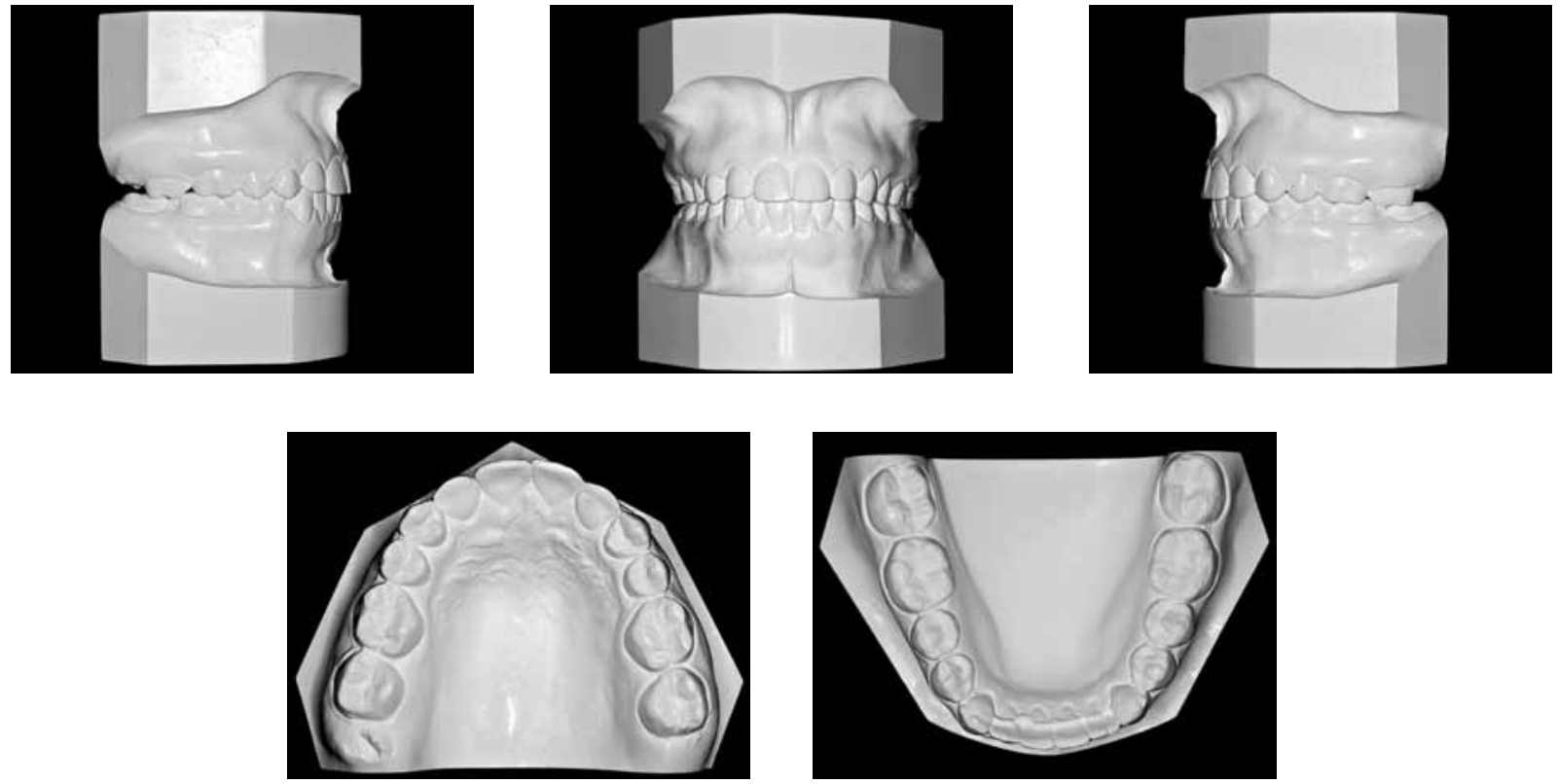

FIGURE 6 - Final casts.
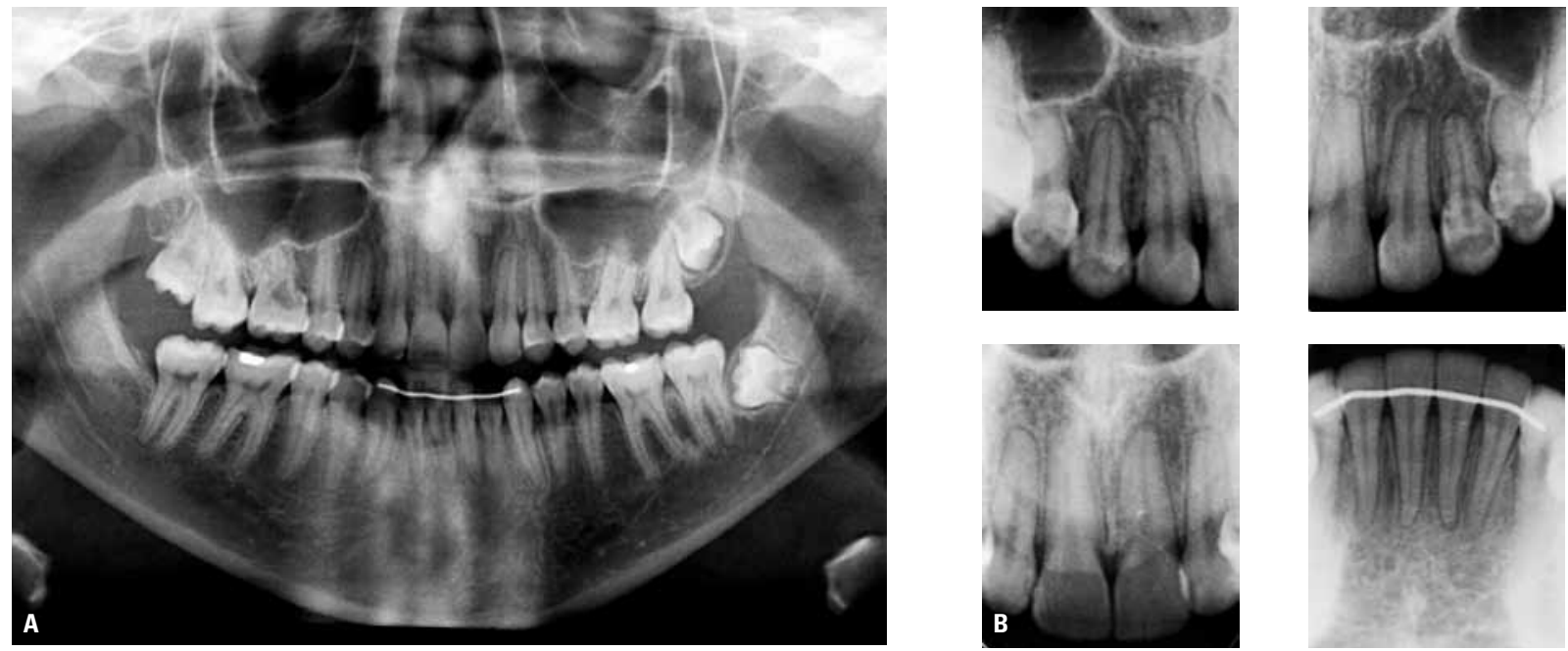

FIGURE 7 - Final panoramic (A) and periapical (B) radiographs. 

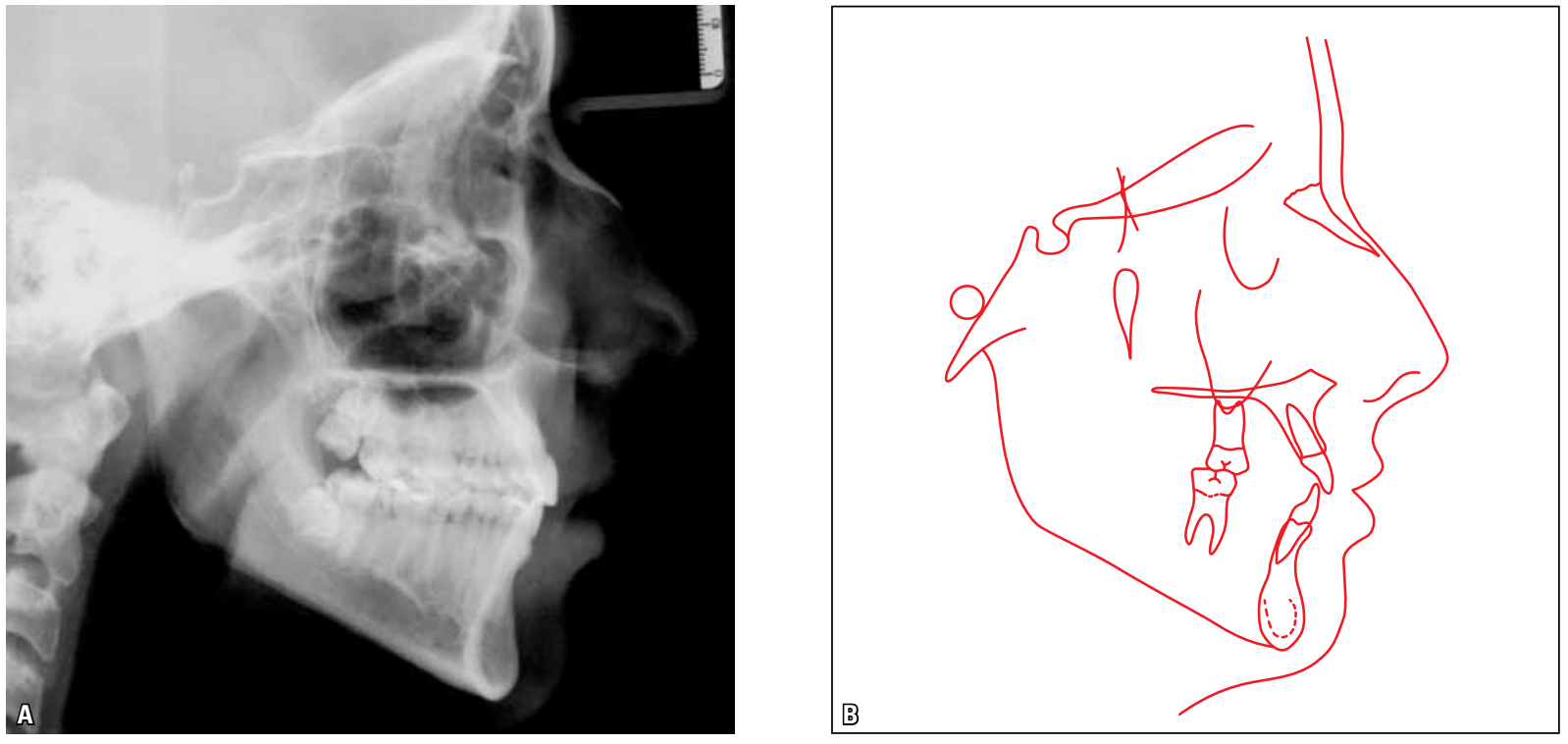

FIGURE 8 - Final lateral cephalometric radiograph (A) and cephalometric tracing (B).
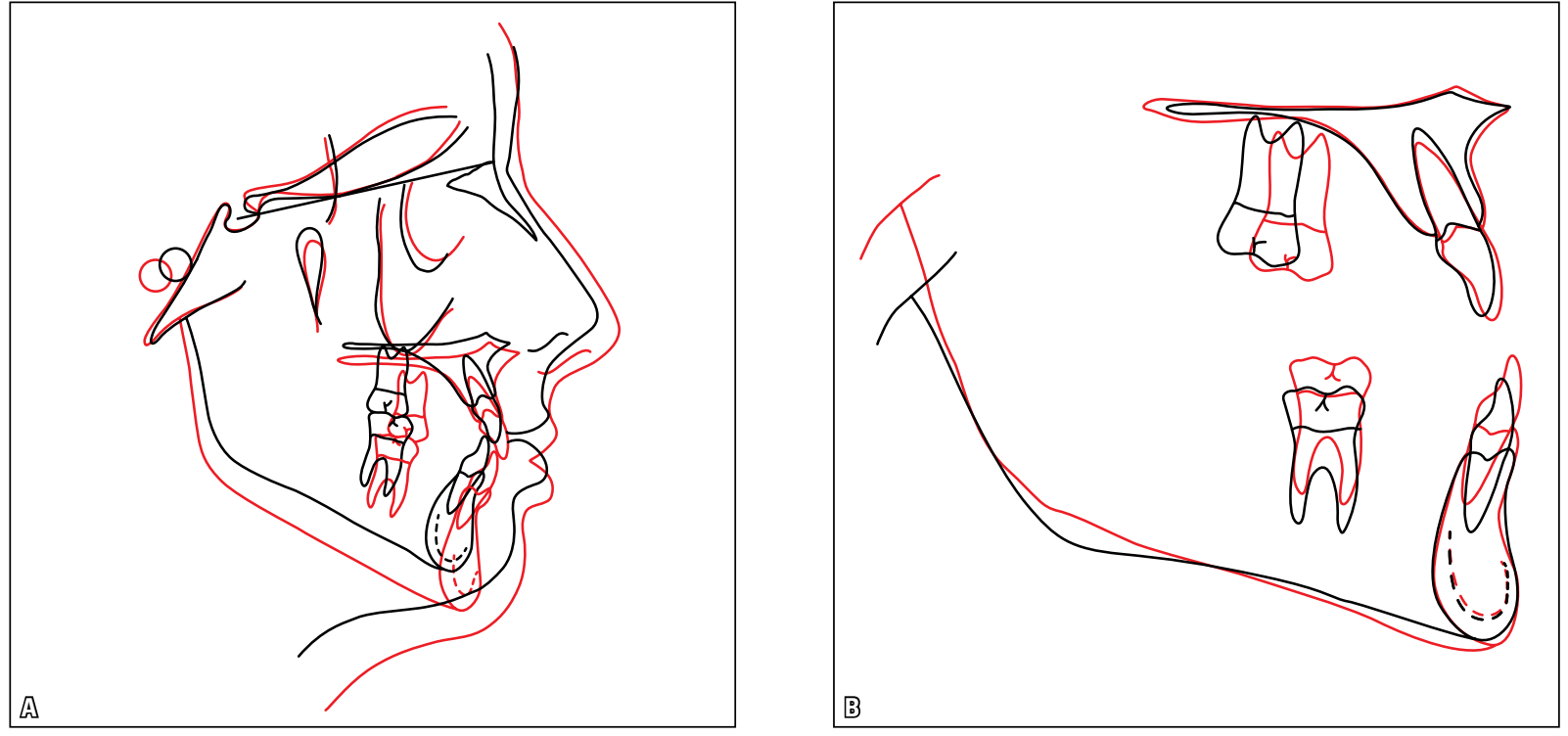

FIGURE 9 - Total (A) and partial (B) superimpositions of initial (black) and final (red) cephalometric tracings. 
TABLE 1 - Summary of cephalometric measurements.

\begin{tabular}{|c|c|c|c|c|c|}
\hline & MEASUREMENTS & Normal & $\mathbf{A}$ & B & $\begin{array}{c}\text { A/B } \\
\text { DIFFERENCE }\end{array}$ \\
\hline \multirow{8}{*}{ 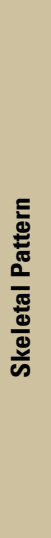 } & SNA (Steiner) & $82^{\circ}$ & $76^{\circ}$ & $76^{\circ}$ & 0 \\
\hline & SNB (Steiner) & $80^{\circ}$ & $74^{\circ}$ & $74^{\circ}$ & 0 \\
\hline & ANB (Steiner) & $2^{\circ}$ & $2^{\circ}$ & $2^{\circ}$ & 0 \\
\hline & Convexity angle (Downs) & $0^{\circ}$ & $3^{\circ}$ & $1^{\circ}$ & 2 \\
\hline & $Y$ axis (Downs) & $59^{\circ}$ & $52^{\circ}$ & $60^{\circ}$ & 8 \\
\hline & Facial angle (Downs) & $87^{\circ}$ & $90^{\circ}$ & $87^{\circ}$ & 3 \\
\hline & SN-GoGn (Steiner) & $32^{\circ}$ & $40^{\circ}$ & $39^{\circ}$ & 1 \\
\hline & FMA (Tweed) & $25^{\circ}$ & $22^{\circ}$ & $24^{\circ}$ & 2 \\
\hline \multirow{7}{*}{ 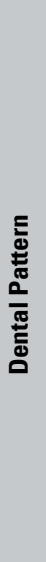 } & IMPA (Tweed) & $90^{\circ}$ & $88^{\circ}$ & $90^{\circ}$ & 2 \\
\hline & $\underline{1}$ - NA (degrees) (Steiner) & $22^{\circ}$ & $29^{\circ}$ & $27^{\circ}$ & 2 \\
\hline & $\underline{1}-\mathrm{NA}(\mathrm{mm})$ (Steiner) & $4 \mathrm{~mm}$ & $4 \mathrm{~mm}$ & $6 \mathrm{~mm}$ & 2 \\
\hline & $\overline{1}-$ NB (degrees) (Steiner) & $25^{\circ}$ & $22^{\circ}$ & $24^{\circ}$ & 2 \\
\hline & $\overline{1}-\mathrm{NB}(\mathrm{mm})$ (Steiner) & $4 \mathrm{~mm}$ & $4 \mathrm{~mm}$ & $4 \mathrm{~mm}$ & 0 \\
\hline & $\frac{1}{1}-$ Interincisal angle (Downs) & $130^{\circ}$ & $135^{\circ}$ & $132^{\circ}$ & 3 \\
\hline & $\overline{1}-\mathrm{APo}(\mathrm{mm})$ (Ricketts) & $1 \mathrm{~mm}$ & $3 \mathrm{~mm}$ & $3 \mathrm{~mm}$ & 0 \\
\hline \multirow{2}{*}{ 흔 } & Upper lip - S line (Steiner) & $0 \mathrm{~mm}$ & $0.5 \mathrm{~mm}$ & $-0.5 \mathrm{~mm}$ & 1 \\
\hline & Lower lip - S line (Steiner) & $0 \mathrm{~mm}$ & $4 \mathrm{~mm}$ & $2 \mathrm{~mm}$ & 2 \\
\hline
\end{tabular}

\section{FINAL CONSIDERATIONS}

Orthodontic treatment of lateral incisors agenesis has been widely discussed and documented in the literature. The main treatment options are space closure or the maintenance of that space for future implant placement. ${ }^{1,5,7,9,10}$ In planning and treatment, orthodontic space closure may be either indicated or contraindicated depending on the original type of malocclusion. Important factors are the degree of crowding, the size and shape of teeth and the state of the occlusion. ${ }^{1,3,8}$ Both treatment options were presented to our patient and her guardians, and the advantages and disadvantages of each were made clear. Despite the normal initial molar relationship and the trend towards anterior crossbite, the decision to close the space was 
primarily based on the fact that teeth change positions as the individual grows. That growth is not followed by osseointegrated implants, which, moreover, have effects that are similar to that of ankylosed teeth. ${ }^{4,6,8}$ In addition to that, in middle- and long-term studies about the position of implants in the anterior region of the maxilla, there was progressive loss of marginal bone support in the buccal surface, gingival retractions and exposure of the implant margin. $2,7,11,12$ The patient and her guardians also received explanations about the implications of the increase of treatment time and the greater need for collaboration. Another factor that played a role in treatment choice was the anatomy of the patient's maxillary canines, which were light colored and not very large. These factors favor reshaping and the positioning of these teeth as lateral incisors. To change the shape of the canines, a combination of abrasion and composite resin restoration was used. The palatal surface was also adjusted to avoid premature contacts with maxillary lateral incisors, which ensured the correct axial positioning of the teeth and the establishment of occlusion without interference. ${ }^{4}$ Moreover, in treatment finishing, canine torque was corrected to be similar to lateral incisor torque, and ideal torques for the first and second premolars were included. ${ }^{4,10}$ The esthetic result might have been better if the first premolar had been intruded to obtain a greater gingival margin height and to ensure a longer premolar crown, whose shape resembled that of the canines more closely. ${ }^{4}$ However, the restorations of the first premolars were rejected by the patient and her guardians after the evaluation of cost and benefits and long-term restoration results.

The choice of an ideal orthodontic treatment for young patients with missing permanent teeth should be based on a careful evaluation of all factors involved in diagnosis, as well as on the characteristics of each patient. ${ }^{12}$ In this clinical case report, we considered individual characteristics and needs and chose a multidisciplinary approach to ensure that the wanted esthetic and functional objectives were achieved. 


\section{REFERENCES}

1. Al-Anezi SA. Orthodontic treatment for a patient with hypodontia involving the maxillary lateral incisors. Am J Orthod Dentofacial Orthop. 2011;139(5):690-7.

2. Chang $M$, Wennström JL, Odman P, Andersson B. Implant supported single-tooth replacements compared to contralateral natural teeth. Crown and soft tissue dimensions. Clin Oral Implants Res. 1999;10(3):185-94.

3. Cozzani M, Lombardo L, Gracco A. Class III malocclusion with missing maxillary lateral incisors. Am J Orthod Dentofacial Orthop. 2011;139(3):388-96.

4. Iseri $\mathrm{H}$, Solow B. Continued eruption of maxillary incisors and first molars in girls from 9 to 25 years, studied by the implant method. Eur J Orthod. 1996;18(3):245-56.

5. Kokich V. Maxillary lateral incisor implants: planning with the aid of orthodontics. J Oral Maxillofac Surg. 2004;62(9 Suppl 2):48-56.

6. Oesterle LJ, Cronin RJ. Adult growth, aging, and the single-tooth implant. Int J Oral Maxillofac Implants. 2000;15(2):252-60.
7. Robertsson S, Mohlin B. The congenitally missing upper lateral incisor. A retrospective study of orthodontic space closure versus restorative treatment. Eur J Orthod. 2000;22(6):697-710.

8. Rosa M, Zachrisson BU. Integrating esthetic dentistry and space closure in patients with missing maxillary lateral incisors. J Clin Orthod. 2001;35(4):221-34.

9. Schwaninger B, Shaye R. Management of cases with upper incisors missing. Am J Orthod. 1977;71(4):396-405.

10. Suguino R, Furquim LZ. Uma abordagem estética e funcional do tratamento ortodôntico em pacientes com agenesias de incisivos laterais superiores. Rev Dental Press Ortod Ortop Facial. 2002;8(6):119-57.

11. Thilander B, Odman J, Lekholm U. Orthodontic aspects of the use of oral implants in adolescents: a 10-year follow-up study. Eur J Orthod. 2001;23(6):715-31.

12. Zachrisson B. Single implants: optimal therapy for missing lateral incisors? Am J Orthod Dentofacial Orthop. 2004;126(6):A13-5.

Submitted: May 27, 2011

Revised and accepted: July 5, 2011

Contact address

Fernanda Catharino Menezes Franco

Av. ACM, 585, sl. 1307 - Itaigara

CEP: 41.850-000 - Salvador/BA, Brazil

E-mail: f.catharino@uol.com.br 